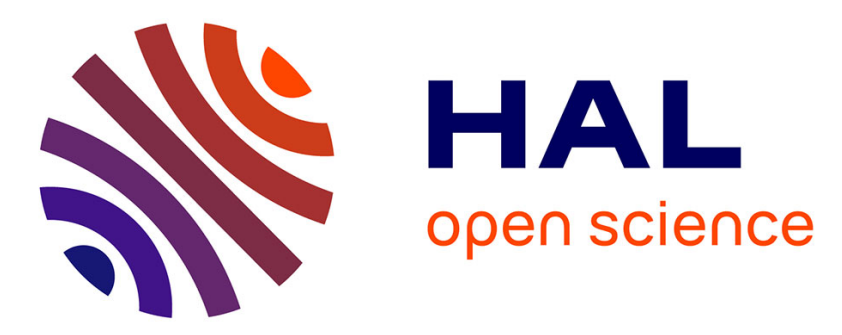

\title{
Optimal design of piezoelectric cantilevered actuators with guaranteed performances by using interval techniques.
}

\author{
Sofiane Khadraoui, Micky Rakotondrabe, Philippe Lutz
}

\section{To cite this version:}

Sofiane Khadraoui, Micky Rakotondrabe, Philippe Lutz. Optimal design of piezoelectric cantilevered actuators with guaranteed performances by using interval techniques.. IEEE/ASME Transactions on Mechatronics, 2014, 19 (5), pp.1660-1668. 10.1109/TMECH.2013.2292494 . hal-01303406

\section{HAL Id: hal-01303406 https://hal.science/hal-01303406}

Submitted on 28 Apr 2016

HAL is a multi-disciplinary open access archive for the deposit and dissemination of scientific research documents, whether they are published or not. The documents may come from teaching and research institutions in France or abroad, or from public or private research centers.
L'archive ouverte pluridisciplinaire HAL, est destinée au dépôt et à la diffusion de documents scientifiques de niveau recherche, publiés ou non, émanant des établissements d'enseignement et de recherche français ou étrangers, des laboratoires publics ou privés. 


\title{
Optimal design of piezoelectric cantilevered actuators with guaranteed performances by using interval techniques
}

\author{
Sofiane Khadraoui, Micky Rakotondrabe, Member, IEEE, and Philippe Lutz, Member, IEEE
}

\begin{abstract}
Piezoelectric materials are well recognized for the development of systems and actuators working at the micro/nanoscale such as microsystems. This recognition is thanks to the high resolution, high bandwidth and high force density that they can offer. However, piezoelectric actuators are typified by low range of displacement relative to other actuators like magnetic or thermal actuators. To obtain sufficient range of displacement with a piezoelectric actuator, either we use high input voltages or we redesign the actuator to have larger dimensions. The former solution may lead to the destruction of the actuators and the latter is not congruent with the objectives of microsystems where the dimensions should be miniaturized. Furthermore, increasing the dimensions of the actuators reduces their rapidity and bandwidth.

This paper proposes an approach based on interval analysis to design piezoelectric actuators with cantilever structures. The aim consists in reducing their dimensions while still satisfying some specified performances in term of output range and in term of resonant frequency (and thus bandwidth). The problem of the design is formulated as a set-inversion problem which can be solved using interval techniques. The obtained results, validated with prototype fabrication and experimental characterization, demonstrate the efficiency and the interests of the proposed method for designing systems and actuators working at the micro/nano-scale in general.
\end{abstract}

Index Terms-Piezoelectric actuators, Design and development, Interval analysis, Bounded parameters, Set-inversion problem, Guaranteed and optimal design, micro and nano-scale.

\section{INTRODUCTION}

$\mathbf{I}$ $\mathrm{N}$ traditional robotics, robots and systems use joints and (DC) motors as principal elements of motion. However, inherent friction in the articulated mechanisms of these robots strongly limits their use in applications that require high accuracy and high resolution such as microrobotic and micromaniplation applications. Consequently, microrobots are generally designed with active or smart materials and deformable structures instead. The advantage is that the resolution of the yielded displacement is highly increased in these structures as the friction is minimized. Additionally to that, the manufacturing of smaller and miniaturized actuators is easier with smart materials and deformable structures than with DC-motors and

The first author was with the Automatic Control and Micro-Mechatronic Systems Department (AS2M) during this work.

The second and third authors are with the Automatic Control and MicroMechatronic Systems Department (AS2M).

FEMTO-ST Institute, UMR CNRS 6174 / UFC / ENSMM / UTBM

24 rue Alain Savary, Besançon 25000, France.

Corresponding author: mrakoton@femto-st.fr

phone: + 33381402 803, fax: + 33381402809 classical joints. Piezoelectric materials are one of the most recognized smart materials used to develop microrobots and systems for micro-nano positioning (precise positioning). This recognition is thanks to the high resolution (up to nanometric level), the high bandwidth (up to tens of kiloHertz) and the high force density they can offer. Furthermore, the ease of power supply (electrical energy) makes their use more generalized. Finally, piezoelectric materials can also be used as sensors [1]-[3] or as simultaneous sensors and actuators (called self-sensing) for applications where the integrating external sensors is impossible [4], [5]. Although the good resolution and the high bandwidth of piezoelectric actuators, one of their limitations is the restricted range of displacement offered (about $0.1 \%$ strain) which is a great disadvantage for some of the above mentionned applications. A technique to overcome this limitation was to employ stepper piezoelectric actuators (stick-slip, inch-worm,...) [6], [7], [7]-[11]. Stepper piezoelectric actuators are well known to provide a large range of displacements. However, as they result from the assembly of several components, these actuators are more complex to develop and their miniaturization is still limited. Therefore, they are generally employed for tasks that really require very large strokes and where there is enough space to place them. Notable complementary systems to stepper piezoelectric actuators are piezoelectric microgrippers which can perform a fine positioning with a very high resolution and a very high speed [12]-[17]. These microgrippers can be utilized as endeffector of the stepper actuators or can work independently [18], [19].

A piezoelectric microgripper is generally composed of two piezoelectric actuators that have cantilevered structures called piezocantilevers. Most of the applications utilize one piezocantilever as the displacement actuator while the second one as the force actuator in order to ensure the precise positioning by controlling the manipulation force [18], [19]. The design of piezoelectric cantilevered structures devoted to micro/nano positioning, microassembly and micromanipulation applications has been addressed in the past [20][23]. These works proposed methodologies to design optimized compliant mechanisms with piezoelectric actuation in order to obtain maximized displacement. These approaches are efficient but find their limitation when the design should account specifications on the structures or on the dimensions. These approaches yielded complex structures in that case. In this paper, we propose a new approach to design piezoelectric actuators that also account the structures and the dimensions 
in the specifications. The approach consists in imposing $a$ priori some wanted performances and some constraints on the geometrical dimensions of the actuators. By combining these specifications with the physical model of the actuator, the proposed design problem is formulated as a set-inversion problem which is solvable using interval techniques. The main advantage of the proposed approach is that if a design solution exists, the specified performances are guaranteed. In fact, such guaranteed performances are inherited from the properties of interval tools and techniques that are used to handle and to solve the problem in this paper. The approach permits therefore to find a set of geometrical sizes within a priori given intervals such that the designed actuator satisfies the specified performances. To demonstrate the approach, an illustrative example of design is proposed. The example consists in redesigning an existing piezocantilever actuator into another one which is more optimized. The designed and optimized actuator will have better performances but smaller dimensions relative to the initial actuator. A prototype is fabricated and experimental characterization on this was carried out, which confirmed the theoretical results.

Interval techniques and related arithmetics have been used in several applications in the past, except for the design of mechanical systems which we intend to propose in this work. According to the history, the first apparition of intervals was in 1897 by Archimedes when he tried to compute the lower and the upper bounds of $\pi$. Further, the idea of using intervals for calculation was proposed in 1924 by Burkill and in 1931 by Young. But, Interval arithmetics became really popular just after the appearance of the R.E. Moore's book in 1966 [24]. This later provided a general method and some formalization of intervals and related arithmetics with an application of automated error analysis. Nowadays, several applications of intervals are devoted to:

- guaranteed estimation [25], [26];

- stability analysis of uncertain systems [27]-[29];

- robust controllers synthesis [30]-[32].

The main interests of intervals and related arithmetics are: the simple and natural way to represent parametric uncertainties by just bounding and their ability to predict a guaranteed set of solution (or non-solution) of design or of controllers that will satsify (or not satisfy) some specifications. This paper utilizes these properties to design piezoelectric actuators such that a more optimized structure (in term of geometrical sizes) than an existing actuator will also provide better performances. The approach can be applied to broader types of actuators but the example carried out in this paper is the design of unimorph piezocantilevers. This permits to show the methodology with an illustrative example.

The paper is organized as follows. Section-II is dedicated to brief preliminaries on intervals. In section-III, we give the analytical model of multimorph piezocantilevers by using points (i.e. not intervals). The model of unimorph piezocantilevers is derived in the same section. In section-IV, we introduce interval analysis to describe the design problem of unimorph piezoelectric actuators. This design problem is formulated as a set-inversion problem and is solved using algorithms and arithmetics of intervals. Finally, section- $\mathrm{V}$ is dedicated to a prototype fabrication and experimental verifications.

\section{BRIEF PRELIMINARIES ON INTERVALS AND THEIR ARITHMETICS}

\section{A. Basic Terms and Concepts on intervals}

More details on the preliminaries given here can be found in [24], [27] or [33].

A closed interval denoted by $[x]$, is the set of real numbers given by:

$$
[x]=\left[x^{-}, x^{+}\right]=\left\{x \in R / x^{-} \leq x \leq x^{+}\right\}
$$

The endpoints $x^{-}$and $x^{+}$are respectively the left and right endpoint of $[x]$. We say that $[x]$ is degenerate if $x^{-}=x^{+}$. By convention, a degenerate interval $[a, a]$ can be described with the number $a$. A degenerate interval number is also called a "point number".

The width of an interval $[x]$ is given by: $w([x])=x^{+}-x^{-}$.

The midpoint of $[\mathrm{x}]$ is given by: $\operatorname{mid}([x])=\frac{x^{+}+x^{-}}{2}$.

The radius of $[x]$ is defined by: $\operatorname{rad}([x])=\frac{x^{+}-x^{-}}{2}$

\section{B. Operations on intervals}

If we have two intervals $[x]=\left[x^{-}, x^{+}\right]$and $[y]=\left[y^{-}, y^{+}\right]$ and a law $\circ \in\{+,-, ., /\}$, we can write:

$$
[x] \circ[y]=\{x \circ y \mid x \in[x], y \in[y]\}
$$

Table I gives the details of the above interval operations.

TABLE I: Arithmetic operations on intervals [24], [27].

\begin{tabular}{|c|l|}
\hline Operation & Definition \\
\hline+ & {$[x]+[y]=\left[x^{-}+y^{-}, x^{+}+y^{+}\right]$} \\
\hline- & {$[x]-[y]=\left[x^{-}-y^{+}, x^{+}-y^{-}\right]$} \\
\hline$*$ & $\begin{array}{l}{[x] *[y]=\left[\min \left\{x^{-} * y^{-}, x^{+} * y^{-}, x^{-} * y^{+}, x^{+} * y^{+}\right\},\right.} \\
\left.\max \left\{x^{-} * y^{-}, x^{+} * y^{-}, x^{-} * y^{+}, x^{+} * y^{+}\right\}\right]\end{array}$ \\
\hline$/$ & {$[x] /[y]=[x] *\left[1 / y^{+}, 1 / y^{-}\right], 0 \notin[y]$} \\
\hline
\end{tabular}

The intersection of two intervals $[x] \cap[y]$ is as follows.

1- If $y^{+}<x^{-}$or $x^{+}<y^{-}$the intersection is the empty set:

$$
[x] \cap[y]=\emptyset
$$

2- Otherwise:

$$
[x] \cap[y]=\left[\max \left\{x^{-}, y^{-}\right\}, \min \left\{x^{+}, y^{+}\right\}\right]
$$

In the latter case, the union of $[x]$ and $[y]$ is also an interval:

$$
[x] \cup[y]=\left[\min \left\{x^{-}, y^{-}\right\}, \max \left\{x^{+}, y^{+}\right\}\right]
$$

When $[x] \cap[y]=\emptyset$, the union of the two intervals is not an interval. For that, the interval hull is defined:

$$
[x] \underline{\cup}[y]=\left[\min \left\{x^{-}, y^{-}\right\}, \max \left\{x^{+}, y^{+}\right\}\right]
$$

An interval hull is therefore the result of the union of two non-connected intervals.

It is verified that: $[x] \cup[y] \subseteq[x] \underline{\cup}[y]$ for any two intervals $[x]$ and $[y]$. 


\section{ANAlyticAl (POINTS) MODELS OF PIEZOCANTILEVERS}

In this section, we first present the linear static and dynamic models of multimorph piezocantilevers by utilizing the approach of Ballas [34]. From that, we derive the static and dynamic models of unimorph piezocantilevers. These models will be used in the next sections for the design of a new unimorph piezocantilever with smaller sizes and that will be able to provide better performances than an existing unimorph. The choice of studying unimorph piezocantilevers as illustrative example is related to their simplicity of fabrication and their wide use in microsystems. Although, the proposed design methodology can be applied to other types of actuators subjected that their models are available. Piezoelectric materials, in particular piezoelectric ceramics, exhibit nonlinearities (hysteresis and creep). These nonlinearities will not be tackled in this paper. In fact, this paper deals with the design of piezoelectric cantilevered actuators that will be able to achieve some desired performances in term of output range for a given maximal input voltage (static characteristic) and in term of first resonant frequency (dynamic characteristic). The effect of the hysteresis is negligible on such performances because only the extremum values of the output are important to evaluate the range. A linear model is sufficient to understand the maximal furnishable range of deflection and a more complicated and nonlinear model would not bring additional information. We therefore propose in the paper to use the standard and traditional linear model. In a control point of view however (feedforward of feedback), introducing the nonlinearities in the model is essential in order to achieve other performances like accuracy or stability.

\section{A. Static and dynamic models of multimorph piezocantilevers}

A multimorph, also called a multilayered, piezocantilever is a cantilever made up of several layers. At least, one of these layers is piezoelectric. The piezoelectric layers are called active layers while the non-piezoelectric layers are called passive layers. Passive layers also serve as electrodes. When an electric voltage is applied to the piezoelectric layers, the whole cantilever bends. The static and dynamic behavior and models of piezocantilevers have been studied in depth in [34]-[37]. The static behavior is described by the deflection of the piezocantilever versus the applied voltage, while the dynamic behavior mainly concerns the resonant frequencies. In this paper, we adopt the description of multimorph piezocantilevers proposed by Ballas [34]. The main advantage of Ballas's description is that the deflection at any point along the cantilever can be calculated.

Consider a clamped-free multimorph piezocantilever as depicted in Fig. 1. This piezocantilever is composed of $n$ piezoelectric and passive layers glued themselves. The width and thickness of the $i^{t h}$ layer are denoted by $w_{i}$ and $h_{i}$ respectively, while the total length $L$ of all layers is supposed to be similar.

If $U$ denotes the voltage applied to the piezocantilever, the deflection $\delta(x)$ at any point $x$ along the piezocantilever is given by [34]:

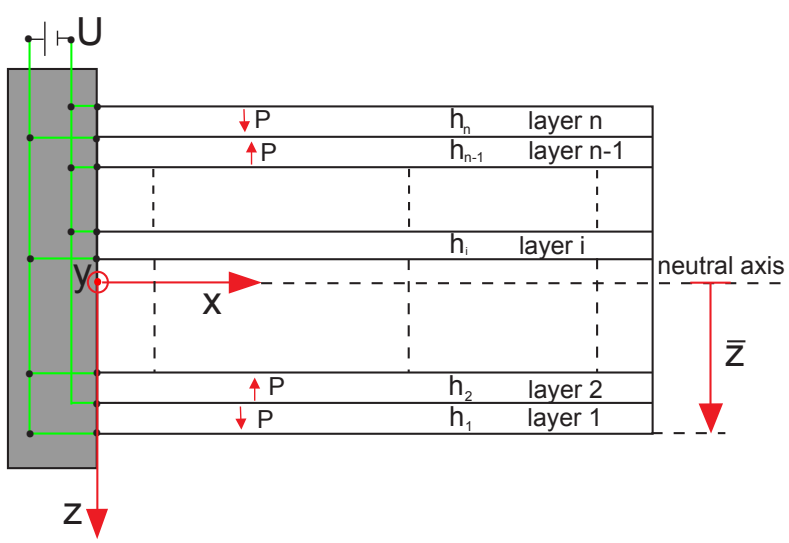

Fig. 1: A clamped-free multimorph piezocantilever.

$$
\delta(x)=\frac{m_{\text {piezo }} x^{2}}{2 C} U
$$

where $m_{\text {piezo }}$ and $C$ are given as follows:

$$
\begin{aligned}
& m_{\text {piezo }}=\frac{1}{2} \sum_{i=1}^{n} \frac{w_{i} d_{31, i}}{s_{11, i} h_{i}}\left[2 \bar{z} h_{i}-2 h_{i} \sum_{j=1}^{i} h_{j}+h_{i}^{2}\right] \\
& C=\frac{1}{3} \sum_{i=1}^{n} \frac{w_{i}}{s_{11, i}}\left[3 h_{i}\left(\bar{z}-\sum_{j=1}^{i} h_{j}\right)\left(\bar{z}-\sum_{j=1}^{i-1} h_{j}\right)+h_{i}^{3}\right]
\end{aligned}
$$

Parameters $s_{11, i}$ represent the piezoelectric or passive compliances at a constant electric field while $d_{31, i}$ represent the piezoelectric constants. $\bar{z}$ in (8) represents the distance between the neutral axis and the lower surface of the piezocantilever and is given by:

$$
\bar{z}=-\frac{\sum_{i=1}^{n} \frac{w_{i}}{s_{11, i}} h_{i}^{2}-2 \sum_{i=1}^{n} \frac{w_{i}}{s_{11, i}} h_{i} \sum_{j=1}^{i} h_{j}}{2 \sum_{i=1}^{n} \frac{w_{i}}{s_{11, i}} h_{i}}
$$

Relation (7) describes the static behavior of the multimorph piezocantilever. The resonant frequency, which describes the dynamics of the actuator, is given by the following expression [34]:

$$
f=\frac{(k L)^{2}}{2 \pi L^{2}} \sqrt{\frac{C}{\sum_{i=1}^{n} \rho_{i} h_{i} w_{i}}}
$$

where $\rho_{i}$ is the density of the $i^{t h}$ layer and $k$ is a constant that satisfies the following equation:

$$
1+\cos (k L) \cosh (k L)=0
$$

An analytic solution of equation (11) is not possible. Numerical solution of (11) leads to $m$ distinct roots $k_{m} L$ $(m=1,2,3, \ldots \infty)$. The subscript $m$ corresponds physically to the number of the appropriate vibratory mode. Table II presents the first five solution $k L$ of (11) [38], [39].

To summarize, the resonant frequencies associated to the modes of the piezocantilever are obtained by means of the 
TABLE II: Solutions of the equation (11).

\begin{tabular}{|c|c|c|c|c|c|c|}
\hline$m$ & 1 & 2 & 3 & 4 & 5 & $\cdots$ \\
\hline$k_{m} L$ & 1.8751 & 4.6941 & 7.8548 & 10.9955 & 14.137 & $\cdots$ \\
\hline
\end{tabular}

characteristic roots $k_{m} L(m=1,2, \ldots)$ given in Table II. The resonant frequency of the $m^{\text {th }}$ mode is given by:

$$
f_{m}=\frac{\left(k_{m} L\right)^{2}}{2 \pi L^{2}} \sqrt{\frac{C}{\sum_{i=1}^{n} \rho_{i} h_{i} w_{i}}}
$$

$k_{m} L$ being defined in Table II.

Many cases only require the first resonant frequency $f_{1}$ (first mode). This first resonant frequency is given by:

$$
f_{1}=\frac{(1.8751)^{2}}{2 \pi L^{2}} \sqrt{\frac{C}{\sum_{i=1}^{n} \rho_{i} h_{i} w_{i}}}
$$

When the number of piezoelectric layers in a multimorph actuator is high, a high range of deflection can be obtained at low voltage. However, the fabrication of the actuator and the wire connection are complex. For the illustrative example of this paper, we propose to restrict our study to the design of unimorph piezocantilevers, only composed of one passive layer and one piezoelectric layer. This does not take off the possibility to generalize the proposed guaranteed design method for other kinds of piezoelectric actuators, or even for other kinds of actuators.

\section{B. Derivation of the static and dynamic models of unimorph piezocantilevers}

A unimorph piezocantilever is made up of one active layer and one passive layer (Fig. 2). The length $L$ and width $w$ are the same for both layers. The thickness of the piezoelectric layer (active layer) is $h_{p}$, while that of the passive layer is $h_{m p}$. In the sequel, we denote:

- $s_{11}^{p}$ and $s_{11}^{m p}$, the compliances of the piezoelectric and of the passive materials respectively;

- $d_{31}$ the piezoelectric constant;

- and $\rho_{p}$ and $\rho_{m p}$ the densities of the piezoelectric and of the passive materials respectively.

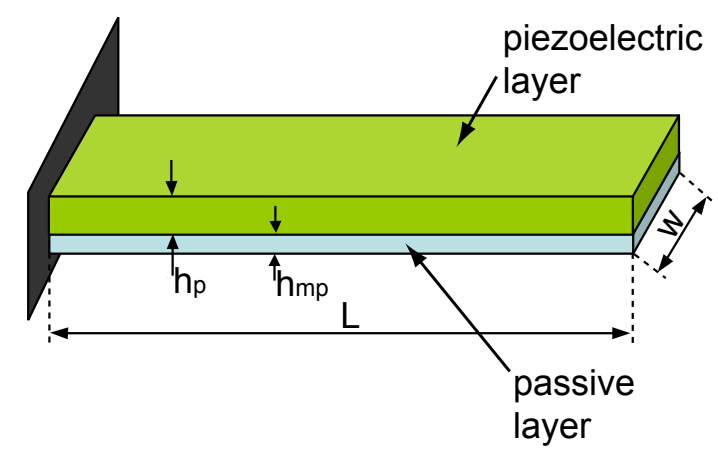

Fig. 2: A unimorph piezocantilever.
After calculation, the static model in (7) becomes the following model for unimorph piezocantilevers:

$$
\delta(x)=\frac{N u m_{\delta}}{\operatorname{Den}_{\delta}}
$$

with:

$$
\begin{aligned}
& N u m_{\delta}=-3 d_{31} s_{11}^{m p} s_{11}^{p} h_{m p}\left(h_{p}+h_{m p}\right) x^{2} U \\
& \operatorname{Den}_{\delta}=\left(s_{11}^{p}\right)^{2} h_{m p}^{4}+\left(s_{11}^{m p}\right)^{2} h_{p}^{4}+s_{11}^{m p} s_{11}^{p}\left(4 h_{p} h_{m p}^{3}+\right. \\
& \left.6 h_{p}^{2} h_{m p}^{2}+4 h_{m p} h_{p}^{3}\right)
\end{aligned}
$$

and the resonant frequencies in (12) becomes:

$$
f_{m}=\frac{\left(k_{m} L\right)^{2}}{2 \pi L^{2}} \sqrt{\frac{D e n_{\delta}}{12 s_{11}^{m p} s_{11}^{p}\left(s_{11}^{m p} h_{p}+s_{11}^{p} h_{m p}\right)\left(\rho_{m p} h_{m p}+\rho_{p} h_{p}\right)}}
$$

Remark 1: These models show that the static and the dynamics beahviors of the piezocantilevered actuator (unimorph and multimorph) strongly depend on the geometrical sizes and on the physical properties. By using these models, it is possible to find convenients dimensions of the actuators that would satisfy some specified performances in term of range of deflection and in term of resonant frequencies. That will be the aim of the next section.

\section{COMBining INTERVAlS AND THE ANALYTICAL MODEL TO DESIGN PIEZOCANTILEVERS}

The previous section was devoted to the modeling of multimorph piezocantilevers with derivation of the models of a unimorph actuator. In this section, we will use these models to design the actuator such that some predefined static and dynamic performances are satisfied. More precisely, the problem consists in finding a set of unimorph with smaller sizes and better performances than a given and existing unimorph. For that, we propose to combine the above analytical models with interval techniques which permits to transform the problem into a set-inversion problem solvable with interval tools. The design is said with guaranteed performances because: if a design solution exists, it is guaranteed that the specifications will be reached.

\section{A. General objective}

Consider an existing unimorph actuator $A_{u 1}$ as pictured in Fig. 3-a. This unimorph has a length $L$, a width $w$ and layers thicknesses $h_{p}$ and $h_{m p}$. The total thickness is $h=h_{p}+h_{m p}$. Let $\delta$ and $f_{1}$ denote the range of deflection obtained with a voltage $U$ and the first resonant frequency of this unimorph. The problem consists in redesigning this actuator into another unimorph $A_{u 2}$ with smaller dimensions (except for the width) denoted by $L_{d} \times w \times h_{d}$ (subscript $d$ means desired) and with better performances for the range of deflection $\delta_{d}$ and for the first resonant frequency $f_{1 d}$ (see Fig. 3-b). The total thickness $h_{d}$ of the unimorph $A_{u 2}$ is calculated with the thickness $h_{d p}$ of the active layer (piezoelectric) and the thickness $h_{d m p}$ of the passive layer: $h_{d}=h_{d p}+h_{d m p}$.

A quick analysis of the models of a unimorph piezocantilever presented in the previous section permits the following remarks: 


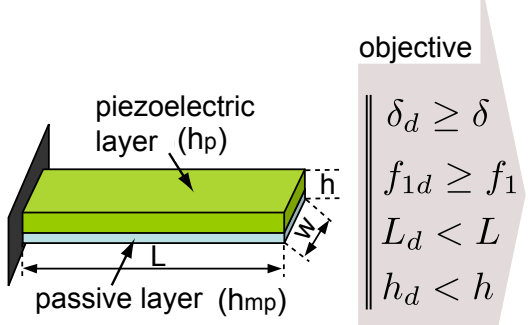

(a)

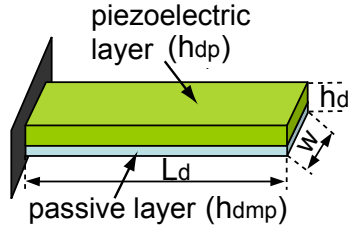

(b)
Fig. 3: a: an existing unimorph piezocantilever $A_{u 1}$. b: the desired unimorph piezocantilever $A_{u 2}$.

- the resonant frequency $f_{m}$ is conversely proportional to the square of its length. Indeed, since $k_{m} L$ is constant (see Table II), the resonant frequency described by (15)) becomes proportional to $\frac{1}{L^{2}}$;

- the deflection is directly proportional to the square of its length. In fact, the deflection, which is described by (14)), is proportional to $x^{2}$. Hence, if we are interested on the deflection at the tip of the cantilever, we have $\delta(x=L)$ proportional to $L^{2}$.

Therefore decreasing the length will yield an increase of the resonant frequency. However, the range of deflection will be reduced. A compensation for this range reduction without disrupting the resonant frequency may be accomplished by some setting on the thicknesses of the piezoelectric and passive layers. Such problem cannot be solved manually but in this paper, this is accounted automatically.

\section{B. Specifications for the design}

Let $\delta(L)$ and $\delta\left(L_{d}\right)$ be the deflections at the tip of the unimorph actuators $A_{u 1}$ and $A_{u 2}$ respectively. Remind that $f_{1}$ and $f_{d 1}$ denote their first resonant frequencies. The specifications for the design consist in finding suitable dimensions $\left(L_{d}\right.$, $h_{d p}$ and $h_{d m p}$ ) of the unimorph $A_{u 2}$ for which the following requirements hold:

- the same materials (piezoelectric and passivle) than those of the existing unimorph $A_{u 1}$ are used of the unimorph $A_{u 2}$;

- the length of the unimorph $A_{u 2}$ must be smaller than that of the unimorph $A_{u 1}$. We choose $L_{d}=\frac{L}{\alpha}$, where $\alpha>1$ is a given scalar $(\alpha \in \mathbb{R})$;

- the total thickness of the unimorph $A_{u 2}$ must be lower or equal to that of the unimorph $A_{u 1}: h_{d}=h_{d p}+h_{d m p} \leq$ $h=h_{p}+h_{m p}$;

- the deflection at the tip of the unimorph $A_{u 2}$ must be higher or equal to that of the unimorph $A_{u 1}$ when the same voltage is applied: $\delta_{d}\left(L_{d}\right) \geq \delta(L)$;

- and the first resonant frequency of the unimorph $A_{u 2}$ must be higher or equal to that of the unimorph $A_{u 1}$ : $f_{d 1} \geq f_{1}$.

From the models in (14) and (15), we see that the width $w$ does not influent on the range and on the resonant frequencies. This parameter will not therefore be introduced in the design problem. Instead, we will impose the width of $A_{u 2}$ be equal to the width of $A_{u 1}$. The remaining parameters to be sought for are the dimensions $L_{d}, h_{d p}$ and $h_{d m p}$.

\section{Problem formulation using inequalities}

If we fix the parameter $\alpha$ in $L_{d}=\frac{L}{\alpha}$, the number of variables (parameters) to be sought for during the further computation is reduced into two: the thicknesses $h_{d p}$ and $h_{d m p}$. If required, it is still possible to let $L_{d}$ as also an unknown parameter.

Based on the static and dynamic modeling of unimorph piezocantilevers presented previously, the specifications, requirements and objectives given in Subsection IV-B can be mathematically transcribed into the following problem.

Problem: Find $h_{d p}$ and $h_{d m p}$ such that:

$$
\left\{\begin{array}{l}
\frac{m_{\text {piezo }}\left(h_{d p}, h_{d m p}\right)\left(\frac{L}{\alpha}\right)^{2}}{2 C\left(h_{d p}, h_{d m p}\right)} U \geq \frac{m_{\text {piezo }}\left(h_{p}, h_{m p}\right) L^{2}}{2 C\left(h_{p}, h_{m p}\right)} U \\
\frac{(1.8751)^{2}}{2 \pi\left(\frac{L}{\alpha}\right)^{2}} \sqrt{\frac{C\left(h_{d p}, h_{d m p}\right)}{w\left(\rho_{m p} h_{d m p}+\rho_{p} h_{d p}\right)}} \geq \\
\frac{(1.8751)^{2}}{2 \pi L^{2}} \sqrt{\frac{C\left(h_{p}, h_{m p}\right)}{w\left(\rho_{m p} h_{m p}+\rho_{p} h_{p}\right)}} \\
h_{d p}+h_{d m p} \leq h
\end{array}\right.
$$

which are equivalent to the following inequalities:

$$
\left\{\begin{array}{l}
\frac{m_{\text {piezo }}\left(h_{d p}, h_{d m p}\right)}{\alpha^{2} C\left(h_{d p}, h_{d m p}\right)} \geq \frac{m_{\text {piezo }}\left(h_{p}, h_{m p}\right)}{C\left(h_{p}, h_{m p}\right)} \\
\alpha^{4} \frac{C\left(h_{d p}, h_{d m p}\right)}{w\left(\rho_{m p} h_{d m p}+\rho_{p} h_{d p}\right)} \geq \frac{C\left(h_{p}, h_{m p}\right)}{w\left(\rho_{m p} h_{m p}+\rho_{p} h_{p}\right)} \\
h_{d p}+h_{d m p} \leq h
\end{array}\right.
$$

\section{Problem formulation using intervals}

The set of thickness $h_{d}=h_{d p}+h_{d m p}$ that satisfies the inequality $h_{d} \leq h$ can be expressed by an interval $\left[h_{d}\right]=[0, h]$. In other words, the thickness of each layer of the unimorph $A_{u 2}$ (i.e. $h_{d p}$ and $h_{d m p}$ ) is bounded by the total thickness $h$. This allows to represent the parameters $h_{d p}$ and $h_{d m p}$ by the intervals $\left[h_{d p}\right]$ and $\left[h_{d m p}\right]$ respectively. When interval parameters are used, the inequalities can be transformed as a system of inclusions. Thus, the design problem defined by inequalities in (17) can be reformulated as follows. 
Consider $[\boldsymbol{\theta}]=\left[\left[h_{d p}\right],\left[h_{d m p}\right]\right]$ as a box (vector of intervals) with elements: $\left[h_{d p}\right]$ and $\left[h_{d m p}\right]$. Let $\Theta$ be the set of parameters $\left[h_{d p}\right]$ and $\left[h_{d m p}\right]$ that satisfies the inequalities (17). So, the problem, when formulated with intervals, consists in finding the suitable values of $[\boldsymbol{\theta}]$ such that:

$$
\Theta:=\{\theta \in \mathbf{D} \quad \mid[H](\theta) \subseteq[\mathbf{Y}]\}
$$

where $\mathbf{D}$ is the domain of definition of $\theta .[H](\theta)$ and $[\mathbf{Y}]$ are defined as follows:

$$
[H](\theta)=\left(\begin{array}{l}
\frac{m_{\text {piezo }}\left(\left[h_{d p}\right],\left[h_{d m p}\right]\right)}{\alpha^{2} C\left(\left[h_{d p}\right],\left[h_{d m p}\right]\right)}-\frac{m_{\text {piezo }}\left(h_{p}, h_{m p}\right)}{C\left(h_{p}, h_{m p}\right)} \\
\frac{\alpha^{4} C\left(\left[h_{d p}\right],\left[h_{d m p}\right]\right)}{\left(\rho_{m p}\left[h_{d m p}\right]+\rho_{p}\left[h_{d p}\right]\right)}-\frac{C\left(h_{p}, h_{m p}\right)}{\left(\rho_{m p} h_{m p}+\rho_{p} h_{p}\right)} \\
h-\left[h_{d p}\right]-\left[h_{d m p}\right]
\end{array}\right)
$$

and

$$
[\mathbf{Y}]=\left(\begin{array}{l}
{[0,+\infty]} \\
{[0,+\infty]} \\
{[0,+\infty]}
\end{array}\right)
$$

The problem of finding the set parameter $[\boldsymbol{\theta}]$ that ensures (18) is a set-inversion problem and can be solved using interval techniques. The set-inversion operation consists to compute the reciprocal image of a compact set called subpaving. The setinversion algorithm SIVIA (Set Inversion Algorithm Via Interval Analysis [25], [27]) allows to approximate with subpavings the set solution $\Theta$ described by (18). This approximation is realized with an inner and outer subpavings, denoted by $\underline{\Theta}$ and $\bar{\Theta}$ respectively, such that $\underline{\Theta} \subset \Theta \subset \bar{\Theta}$. The subpaving $\Theta$ corresponds to the parameter vector for which the problem (18) holds. If $\Theta=\emptyset$, then it is guaranteed that no solution exists for (18). If a solution $\Theta$ exists, it is guaranteed that any parameters $\left(\left[h_{d p}\right]\right.$ and $\left.\left[h_{d m p}\right]\right)$ inside this set will satisfy the desired specifications in (17).

In many problems (signal estimation, control design,...) [25], [26] [30]-[32], interval tools, in particular the SIVIA algorithm, have been demonstrated theoretically and with experiments to guarantee the efficiency of the solution, if this exists. This is one of the major advantages of interval techniques and tools. In our case, if the solution $\Theta$ exists, it is guaranteed that the unimorph actuator with parameters within this solution will satisfy the specifications.

We give in Table III the recursive SIVIA algorithm used to solve the design problem of piezocantilevers (18) with guaranteed solution and guaranteed non-solution. SIVIA algorithm requires a search box $[\theta](0)$ (possibly very large). The search box is also called initial box and $\bar{\Theta}$ may belong to this. The inner and outer subpavings $(\underline{\Theta}$ and $\bar{\Theta})$ are initially empty. $\epsilon$ represents the wanted accuracy of computation.

In the most cases, we are interested to compute an inner subpaving $\underline{\Theta}$ because it is guaranteed that $\underline{\Theta}$ is enclosed in the $\Theta$, i.e. $\underline{\Theta} \subset \Theta$. When no inner subpaving exists i.e. $\underline{\Theta}=\emptyset$, it is possible to choose parameters inside the outer subpaving, i.e. choose $\theta \in \bar{\Theta}$.
TABLE III: SIVIA Algorithm [25], [27] which is modified to fit with the set-inversion problem described by (18).

\begin{tabular}{|c|l|}
\hline & SIVIA(in: $[H],[\mathbf{Y}],[\theta], \epsilon ;$ out: $\underline{\Theta}, \bar{\Theta})$ \\
\hline 1 & if $[H](\theta) \cap[\mathbf{Y}]=\emptyset$ return; \\
2 & if $[H](\theta) \subseteq[\mathbf{Y}]$ then; \\
& $\{\underline{\Theta}:=\underline{\Theta} \bigcup[\boldsymbol{\theta}] ; \bar{\Theta}:=\bar{\Theta} \bigcup[\boldsymbol{\theta}]\}$ return; \\
4 & if width $([\theta])<\epsilon$ then $\{\bar{\Theta}:=\bar{\Theta} \bigcup[\theta]\} ;$ return; \\
5 & bisect $[\theta]$ into $L([\theta])$ and $R([\theta]) ;$ \\
6 & SIVIA $([H],[\mathbf{Y}], L([\theta]), \epsilon ; \underline{\Theta}, \bar{\Theta}) ;$ \\
& $\operatorname{SIVIA}([H],[\mathbf{Y}], R([\theta]), \epsilon ; \underline{\Theta}, \bar{\Theta})$.
\end{tabular}

\section{NUMERICAL CALCULATION, PROTOTYPE FABRICATION AND EXPERIMENTAL VERIFICATIONS}

This section is devoted to the numerical calculation, the fabrication of a prototype and the experimental validation.

\section{A. Materials}

First, we present here the materials that compose the layers of the existing unimorph. The piezoelectric material used is based on PZT (lead zirconate titanate) commercially available (from Physike Instrumente (PI) company). The passive layer is based on Nickel material from Goodfellow company. The same materials will be employed to develop the designed unimorph $A_{u 2}$. The product of reference "EPO-TEK H22" from $P I$ is used to glue the piezoelectric and passive layers and to form the new PZT-Nickel unimorph piezocantilever. This is a thermal glue with which the gluing is performed at $120^{\circ} \mathrm{C}$ during $12 \mathrm{~h}$. With this procedure, we have a very thin film and a robust interface between the two materials. If the glue layer is not thin enough, its thickness will affect the behavior (resonant frequency and range of deflection) of the unimorph structure. Table IV summarizes some physical properties of the PZT and of the Nickel materials.

TABLE IV: Physical characteristics of PZT and Nickel materials.

\begin{tabular}{|l|c|c|c|}
\hline materials & compliance & piezoelectric & density $\rho$ \\
& $s_{11}$ & constant $d_{31}$ & \\
\hline PZT & $15 \times 10^{-12} \mathrm{~m}^{2} / \mathrm{N}$ & $-210 \times 10^{-12} \mathrm{~m} / \mathrm{V}$ & $7800 \mathrm{~kg} / \mathrm{m}^{3}$ \\
Nickel & $5 \times 10^{-12} \mathrm{~m}^{2} / \mathrm{N}$ & 0 & $8900 \mathrm{~kg} / \mathrm{m}^{3}$ \\
\hline
\end{tabular}

The unimorph $A_{u 1}$ that is initially available and to be redesigned into another unimorph $A_{u 2}$ has the following characteristics.

- length: $L=20 \mathrm{~mm}$;

- thicknesses: $h_{p}=450 \mu \mathrm{m}$ and $h_{m p}=200 \mu \mathrm{m}$;

- width: $w=1 \mathrm{~mm}$.

For the example of redesign, we set $\alpha=2$ such that the desired length $L_{d}$ is twice smaller than the initial length $L$ :

$$
L_{d}=\frac{L}{\alpha}=\frac{20 \mathrm{~mm}}{2}=10 \mathrm{~mm}
$$

Finally, the width of the unimorph $A_{u 2}$, which is considered equal to the width of the unimorph $A_{u 1}$, is: $w=1 \mathrm{~mm}$. Now, 
we solve the problem (18) with the two remaining unknown parameters $\left[h_{d p}\right]$ and $\left[h_{d m p}\right]$.

\section{B. Solving the set-inversion problem}

The problem (18), using the above numerical values, has been solved using an initial box $\left[h_{d p}\right]_{0} \times\left[h_{d m p}\right]_{0}=[10,640] \times$ $[10,640]$ and an accuracy $\epsilon=1 \mu \mathrm{m}$. The solving has been done with the SIVIA algorithm (see Table IV). Fig. 4 pictures the results from the algorithm.

In this figure, the area $S_{1}$ corresponds to the guaranteed solution (inner subpaving $\underline{\Theta}$ ), i.e. the set $h_{d p} \times h_{d m p}$ of the wanted unimorph $A_{u 2}$ that satisfies the specified performances. Any choice of $h_{d p}$ and $h_{d m p}$ inside the subpaving $\underline{\Theta}$ ensures the inclusions given in (18). The area $S_{2}$ corresponds to $\Delta \Theta$ and contains the boxes for which no decision can be taken, such that: $\bar{\Theta}=\underline{\Theta} \cup \Delta \Theta . \Delta \Theta$ can be minimized by increasing the computation accuracy. Finally, the area in $S_{3}$ corresponds to the parameters $\left[h_{d p}\right]$ and $\left[h_{d m p}\right]$ for which it is guaranteed that the inclusions (18) do not hold.

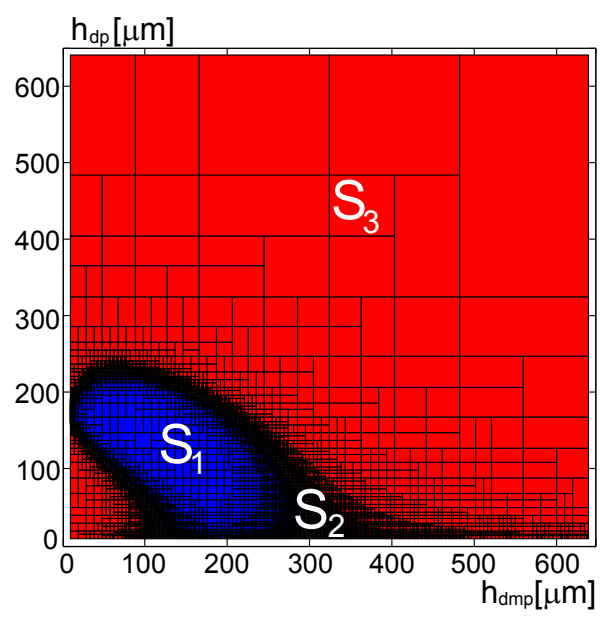

Fig. 4: Set solution $\underline{\Theta}$ corresponding to the parameters $h_{d p}$ and $h_{d m p}$.

\section{Fabrication of the unimorph and experimental verifications}

$S_{1}$ region in Fig. 4 depicts a set of solution of $h_{d p} \times h_{d m p}$ with which a unimorph piezocantilever will satisfy the specifications in Subsection IV-B. In order to demonstrate the efficiency of the approach, a prototype of unimorph having dimensions within this set solution is fabricated. We choose:

$$
\left\{\begin{array}{l}
L_{d}=10 \mathrm{~mm} \\
h_{d p}=200 \mu \mathrm{m} \\
h_{d m p}=100 \mu \mathrm{m} \\
w=1 \mathrm{~mm}
\end{array}\right.
$$

Fig. 5-a presents a photography of the fabricated unimorph piezocantilever.

To check the performances, a static and a harmonic analysis have been carried out with the fabricated unimorph $A_{u 2}$ and

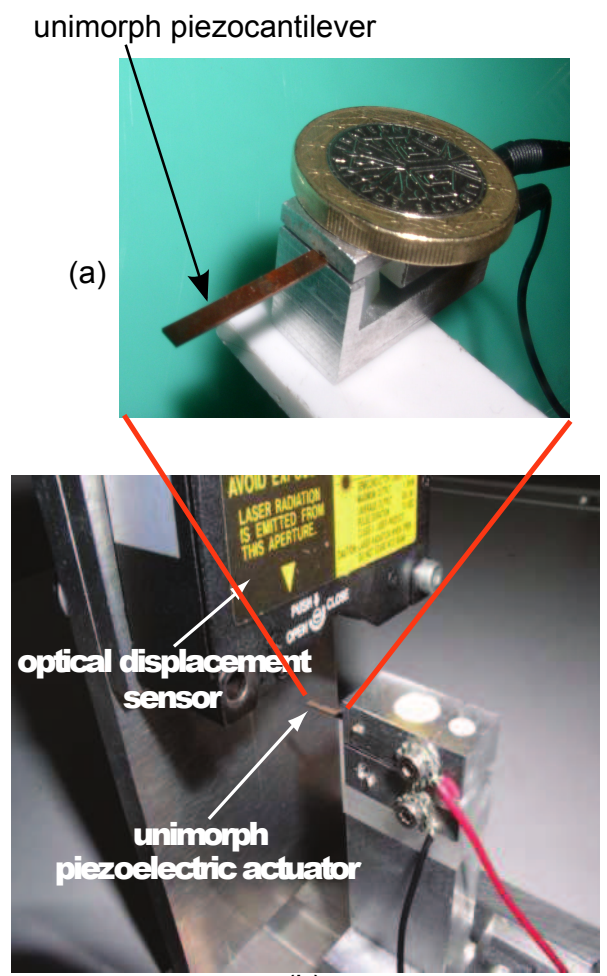

(b)

Fig. 5: a: photography of unimorph piezocantilevers. b: experimental setup.

with the existing unimorph piezocantilever $A_{u 1}$. A comparison and discussion on their performances were afterwards done.

Fig. 5-b pictures the experimental setup which is composed of:

- a unimorph piezocantilever. Both the existing unimorph $A_{u 1}$ and the designed unimorph $A_{u 2}$ are characterized with this same setup;

- an optical sensor (from Keyence company) with resolution of $10 \mathrm{~nm}$ and which is used to measure the deflection of the piezocantilevers;

- and a dSPACE acquisition board and a computer to generate the input voltage and to acquire the measurements.

The first experiment consists in evaluating the range of deflection (static characteristic) of the actuators. For that, a sine input voltage $U$ is applied to the actuators and the resulting output deflection $\delta$ is reported. The range can be evaluated from the plot of $\delta$ versus $U$. As this experiment concerns the static characteristic, the frequency $f$ of the sine input voltage should be low. In fact, if we increase the frequency, the dynamics of the actuators will affect the resulting $(U, \delta)$ curve and then the static characteristic can not be anymore evaluated due to the phase-lag. For the considered actuators, a sine voltage of frequency $f=2 \mathrm{~Hz}$ was convenient. The amplitude is $U=40 \mathrm{~V}$. This sine voltage was applied to the unimorph $A_{u 1}$, and then to the unimorph $A_{u 2}$. Fig. 6-a depicts the deflection of the designed unimorph $A_{u 2}$ versus the voltage $U$.

Then, the second experiments consist in performing a harmonic analysis. The aim is to characterize the first resonant 
frequencies of the unimorphs. Fig. 6-b depicts the results obtained with the designed unimorph $A_{u 2}$.

Table V summarizes the results of characterization of both unimorph piezocantilevers. In the table, both simulation and experimental results are reported. From this table, the maximum deflection of the designed unimorph $A_{u 2}$ (in excess of $10 \mu \mathrm{m}$ ) and its resonant frequency (in excess of $1600 \mathrm{~Hz}$ ) are higher than those of the unimorph $A_{u 1}$ (about $8 \mu \mathrm{m}$ and $960 \mathrm{~Hz}$ respectively). Also, the geometrical dimensions of the unimorph $A_{u 2}$ are strictly less than those of the unimorph $A_{u 1}$. This confirms that the specifications are ensured. We can see from the table a slight difference between the simulation results and the experimental results, in particular for the designed actuator $A_{u 2}$. This difference may be due to the thickness of the glue used to interface the piezoelectric material and the passive material. Although this slight difference, the experimental results confirm and demonstrate the efficiency of the approach. These experimental and simulation results confirm the proposed approach to design the piezoelectric actuator.
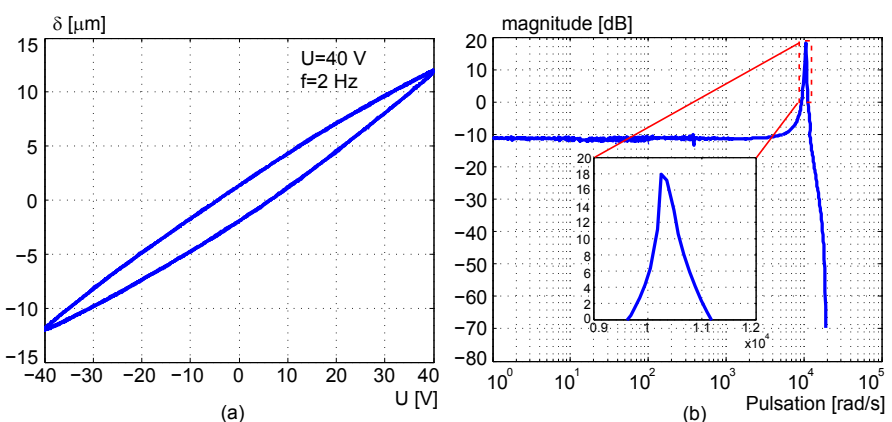

Fig. 6: a: static characteristic of the fabricated prototype unimorph $A_{u 2}$. b: frequency response (magnitude) of the fabricated prototype unimorph $A_{u 2}$.

Remark 2: It is possible to design other kinds of piezoelectric actuators with the proposed approach, like bimorph piezocantilevers. A bimorph piezocantilever provides a larger deflection compared to that of a unimorph when the same voltage is applied. However, bimorph piezocantilevers present more complex electric connections and are difficult to fabricate. The fabrication simplicity of unimorph piezocantilevers makes them widely used in the precise positioning. This is why the example carried out in this paper concerns unimorph actuators.

Remark 3: The technique proposed in this paper can also be used to other kinds of actuators (different from piezoelectric actuators), or even to non-actuated structures. As long as a physical and geometrical model is available, the technique consists in combining the model with interval techniques which can be afterwards solved thanks to a set-inversion algorithm.

Remark 4: In this paper, the performances used for the design were the range of displacement and the first resonant frequency. It is however possible to apply the proposed design methodology with other kinds of performances, for instance with the accuracy or with the resolution. Finally, an interesting problem consists in designing an actuator yet in a feedback control scheme having a given controller. In this case, the problem comes back to the design of the actuator such that the closed-loop possesses some desired performances like tracking accuracy, limited input voltage, settling time, overshoots...

\section{CONCLUSION}

This paper presented the design of piezoelectric actuators by using interval techniques. The main goal was to redesign an existing piezoelectric actuator (unimorph) in order to have a new unimorph actuator having smaller sizes but that would provide better performances. The problem was formulated as a set-inversion problem that was solved using interval techniques. The main advantage of the proposed approach is the guarantee of the performances if solution exists. Fabrication of a prototype and experimental characterization confirmed the efficiency of the proposed approach. The paper described as illustrative example the design of unimorph piezoelectric actuators, but the approach can be applied to other kinds of actuators subjected that their physical/geometrical models are available.

\section{REFERENCES}

[1] X. Lin, F. G. Yuan, 'Diagnostic lamb waves in an integrated piezoelectric sensor/actuator plate: analytical and experimental studies', Smart Materials and Structures, vol. 10, pp. 907-913, 2001.

[2] D. Campolo, R. Sahai, R. S. Fearing, 'Development of piezoelectric bending actuators with embedded piezoelectric sensors for micromechanical flapping mechanisms', IEEE Int. Conf. on Robotics and Automation, Taipei, Taiwan, pp. 3339-3346, 2003.

[3] P. J. Costa Branco, J. A. Dente, 'On the electromechanics of a piezoelectric transducer using a bimorph cantilever undergoing asymmetric sensing and actuation', Smart Materials and Structures, vol. 13, pp. 631642, 2004.

[4] M. Rakotondrabe, I. A. Ivan, S. Khadraoui, C. Clévy, P. Lutz, and N. Chaillet, 'Dynamic displacement self-sensing and robust control of cantilevered piezoelectric actuators dedicated to microassembly tasks', in Proc. IEEE/ASME Int. Conf. Intell. Mater., AIM, Montreal, Canada, pp. 557-562, 2010.

[5] X. Ma, W. Dong, X. Ding, P. Zhang, C. Yan, 'Piezoelectric self-sensing actuator for beam vibration control based on blind source seperation', Asian Meeting on Ferroelectrics, Noda Japon,vol. 358, no. 5, pp. 29-34, 2007.

[6] Micky Rakotondrabe, Yassine Haddab and Philippe Lutz, 'Development, modeling and control of a micro/nanopositioning 2-dof stick-slip device', IEEE Transactions on Mechatronics, Vol.14, no. 6, pp. 733-745, December 2009.

[7] Y.L. Zhang, Y. Zhang, C.H. Ru, and Y. Sun, 'A load-lock-compatible nanomanipulation system for scanning electron', IEEE Trans. on Mechatronics, Vol.18(1), pp.230 - 237, Feb. 2013.

[8] A. Bergander, W. Driesen, T. Varidel, M. Meizoso, and J. M. Breguet. 'Mobile cm3-microbots with tools for nanoscale imaging and micromanipulation', Mechatronics Robotics, Aachen, Germany, September 2004.

[9] S. Fatikow, B. Magnussen, and U. Rembold. 'A piezoelectric mobile robot for handling of microobjects', Microsystems, Intelligent Materials and Robots (MIMRS), Sendai, Japan, September 1995.

[10] http ://www.physikinstrumente.com/.

[11] J-Y Peng and X-B Chen, 'Modeling of piezoelectric-driven stick-slip actuators', IEEE/ASME - Transactions on Mechatronics (T-mech) Vol.16. no. 1, pp. 394-399, April 2011.

[12] B. Edamana, B. Hahn, J.S. Pulskamp, R.G. Polcawich and K. Oldham, 'Modeling and Optimal Low-Power on-off Control of Thin-Film Piezoelectric Rotational Actuators', IEEE/ASME Transactions on Mechatronics, vol. 16, no. 5, pp. 884-896, october 2011.

[13] R.J.E. Merry, M.G.J.M. Maassen, M.J.G. van de Molengraft, N. van de Wouw and M. Steinbuch, 'Modeling and Waveform Optimization of a Nano-motion Piezo Stage', IEEE/ASME Transactions on Mechatronics, vol. 16, no. 4, pp. 615-626, August 2011. 
TABLE V: Comparison of the obtained results.

\begin{tabular}{|c|c|c|c|c|c|c|c|}
\hline piezocantilever & $\begin{array}{c}\text { length of the } \\
\text { piezocantilever }\end{array}$ & $\begin{array}{c}\text { thickness of } \\
\text { the piezo-layer } \\
\text { the piezo-layer }\end{array}$ & $\begin{array}{c}\text { thickness of } \\
\text { the passive layer }\end{array}$ & $\begin{array}{c}\text { maximum } \\
\text { deflection } \\
\text { (experimental) }\end{array}$ & $\begin{array}{c}\text { maximum } \\
\text { deflection } \\
\text { (model simulation } \\
\text { with the dimensions) }\end{array}$ & $\begin{array}{c}\text { resonant } \\
\text { frequency } \\
\text { (experimental) }\end{array}$ & $\begin{array}{c}\text { first resonant } \\
\text { frequency } \\
\text { (model simulation } \\
\text { with the dimensions) }\end{array}$ \\
\hline unimorph $A_{u 1}$ & $L=20 \mathrm{~mm}$ & $h_{p}=450 \mu \mathrm{m}$ & $h_{m p}=200 \mu \mathrm{m}$ & $|\delta| \approx 8.5 \mu \mathrm{m}$ & $|\delta|=8.48 \mu \mathrm{m}$ & $f_{1} \approx 951.67 \mathrm{~Hz}$ & $f_{1}=952.12 \mathrm{~Hz}$ \\
\hline unimorph $A_{u 2}$ & $L_{d}=10 \mathrm{~mm}$ & $h_{d p}=200 \mu \mathrm{m}$ & $h_{d m p}=100 \mu \mathrm{m}$ & $\left|\delta_{d}\right| \approx 12 \mu \mathrm{m}$ & $|\delta|=10.45 \mu \mathrm{m}$ & $f_{1_{d}} \approx 1641 \mathrm{~Hz}$ & $f_{1}=1755.5 \mathrm{~Hz}$ \\
\hline
\end{tabular}

[14] E. Steltz and R.S. Fearing, 'Dynamometer Power Output Measurements of Piezoelectric Actuators', IEEE/ASME Transactions on Mechatronics, vol. 16, no. 4, pp. 1-10, 2009.

[15] Joël Agnus, Nicolas Chaillet, Cédric Clévy, Sounkalo Dembélé, Michaël Gauthier, Yassine Haddab, Guillaume Laurent, Philippe Lutz, Nadine Piat and Micky Rakotondrabe, 'Robotic Microassembly and micromanipulation at FEMTO-ST', Journal of Micro-Nano Mechatronics, in press 2012.

[16] M. Grossard, M. Boukallel, N. Chaillet and C. Rotinat-Libersa, 'Modeling and robust control strategy for a control-optimized piezoelectric microgripper', IEEE/ASME Transactions on Mechatronics, vol. 16, no. 4, pp. 674-683, 2011.

[17] Y. Haddab, N. Chaillet and A. Bourjault, 'A microgripper using smart piezoelectric actuators', IEEE/RSJ International Conference on Intelligent Robot and Systems (IROS), Takamatsu - Japan, 2000.

[18] Micky Rakotondrabe and Alexandru Ivan, 'Development and Force/Position Control of a New Hybrid Thermo-Piezoelectric microGripper dedicated to micromanipulation tasks', IEEE - Transactions on Automation Science and Engineering (T-ASE), Vol.8, Issue.4, pp.824834, 0ctober 2011.

[19] Micky Rakotondrabe, Cédric Clévy and Philippe Lutz, 'Modelling and robust position/force control of a piezoelectric microgripper', IEEE CASE, (International Conference on Automation Science and Engineering), pp:39-44, Scottsdale AZ USA, Sept 2007.

[20] M. Grossard, C. Rotinat-Libersa, N. Chaillet, M. Boukallel, 'Mechanical and Control-Oriented Design of a Monolithic Piezoelectric Microgripper Using a New Topological Optimization Method', vol. 14, no. 1, pp. 32-45, 2009.

[21] S. Bharti, M. Frecker, 'Compliant mechanical amplifier design using multiple optimally placed actuators', Proceedings of IMECEŠ03 ASME International Mechanical Engineering Congress and Exposition, no. IMECE2003-42658, pp. 139-146, 2003.

[22] S. Bharti, M. Frecker, 'Optimal design and experimental characterization of a compliant mechanism piezoelectric actuator for inertially stabilized rifle', Journal of intelligent material systems and structures, vol. 15, no. 2, pp. 93-106, 2004.

[23] P. R. Ouyang, W. J. Zhang, 'Design of a new compliant mechanical amplifier', Proceedings of IDETC/CIE ASME 2005 International Design Engineering Technical Conferences \& Computers and Information in Engineering Conference, Vol. 7, pp. 15-24, 2005.

[24] R. E. Moore, 'Interval Analysis', Prentice-Hall, Englewood Cliffs N. J., 1966.

[25] L. Jaulin and E. Walter, 'Set inversion via interval analysis for nonlinear bounded-error estimation', Automatica, vol. 29, no. 4, pp. 1053-1064, 1993.

[26] L. Jaulin, 'Interval constraint propagation with application to boundederror estimation', Automatica, vol. 36, pp. 1547-1552, 2000.

[27] L. Jaulin, M. Kieffer, O. Didrit, and E. Walter, 'Applied Interval Analysis', Springer, 2001.

[28] E. Walter, L. Jaulin, 'Guaranteed characterization of stability domains via set inversion', IEEE Trans. on Autom. Control, vol. 39, no. 4, pp. 886-889, 1994.

[29] V. L. Kharitonov, 'Asymptotic stability of an equilibrium position of a family of systems of linear differential equations', Differential'nye Uravnenya, vol. 14, pp. 2086-2088, 1978.

[30] S. Khadraoui, M. Rakotondrabe and P. Lutz, 'Interval Modeling and Robust Control of Piezoelectric Microactuators', IEEE - Transactions on Control Systems Technology (T-CST), pp. 1-9, 2011.

[31] S. Khadraoui, M. Rakotondrabe and P. Lutz, 'Combining $H_{\infty}$ approach and interval tools to design a low order and robust controller for systems with parametric uncertainties: application to piezoelectric actuators', International Journal of Control (IJC), to appear.

[32] M. Rakotondrabe, 'Performances inclusion of stable interval systems', ACC American Control Conference, pp. 4367-4372, San Francisco June/July 2011.
[33] R.E. Moore, R.B. Kearfott, M.J. Cloud 'Introduction to Interval Analysis', Society for Industrial and Applied Mathematics, Philadelphia, 2009.

[34] R. G. Ballas, 'Piezoelectric multilayer beam bending actuators : Static and dynamic behavior and aspects of sensor integration', Springer, 2007.

[35] J. G. Smits and W. S Choi, 'The constituent equations of piezoelectric hetrogeneous bimorphs', IEEE Transactions on Ultrasonics, Ferroelectrics and Frequency Control, vol. 38, no. 3, pp. 256-270, 1991.

[36] D. L. DeVoe and A. P. Pis'ano, 'Modeling and optimal design of piezoelectric cantilever microactuators, Journal of Microelectromechanical Systems, vol. 6, no. 3, pp. 266-270, 1997.

[37] M. S. Weinberg, 'Working equations for piezoelectric actuators and sensors', Journal of Microelectromechanical Systems, vol. 8, no. 4, pp. 529-533, 1999.

[38] Y. Tang, 'Numerical evaluation of uniform beam modes', Journal of Engineering Mechanics, vol. 129, no. 12, pp. 1475-1477, 2003.

[39] W. Soedel, 'Vibrations of shells and plates', 2nd ed. Marcel Dekker, New York, 1993. 